NURY GONZÁLEZ ANDREU

DIRECTORA

MAPA, MUSEO DE ARTESANÍA POPULAR AMERICANO

TOMÁS LAGO

SANTIAGO, CHILE

NURYGONZALEZ@GMAIL.COM

1. En 1672, Colbert prohibió la importación de espejos venecianos, lo que demuestra tanto la voluntad de protección de la manufactura nacional como la calidad lograda de los productos fabricados en Francia. En Saint-Gobain se inventó una nueva técnica para fundición de vidrio sobre una mesa de metal, lo que permitió la producción de grandes espejos.

2. Alençon, antigua "Ciudad Ducal", debe su fama internacional a sus trabajos de encaje con un tipo de punto conocido como "punto de Alençon", exclusivo de la fábrica real creada por Colbert.

Cómo citar: González Andreu, N. (2019)

La Revelación de Chile.

RChD: creación y pensamiento, 4 (7), 1-8

DOI: 10.5354/0719-837X.2019.55288

Revista Chilena de Diseño,

RChD: creación y pensamiento

Universidad de Chile

2019, 4(6)

http://rchd.uchile.cl

\section{La revelación de Chile}

The Revelation of Chile

Existe en Francia una importante tradición por valorar las actividades y creaciones artesanales, un impulso de autonomía nacional de muy larga data, ya que es en el siglo XVII durante el reinado de Luis XIV cuando estas prácticas adquieren mayor relevancia y comienza su desarrollo sistemático apoyado por el Estado. Por encargo del rey, Jean-Baptiste Colbert, su ministro de Finanzas, impulsa el surgimiento de las manufacturas nacionales como una forma de independizarse de otros países de Europa para ornamentar y engrandecer las estancias reales. Para lograr este objetivo, que se consideraba de primera prioridad en el desarrollo político e institucional de Francia, Colbert promueve la creación y el desarrollo de fábricas de artesanos que producirían objetos de arte de gran calidad, especialmente diseñados para constituir el espacio de Francia mediante el alajamiento de las casas reales. En esta época empiezan a surgir, $y$ a darse a conocer en el mundo entero, obras de artistas y artesanos franceses que le darán a Francia una identidad de grandeza inigualable, constituyéndola en modelo para la constitución de los estados nacionales.

Son muchos los ámbitos a los cuales se les da apoyo, por ejemplo, en 1665, como una estrategia para competir con la producción veneciana que dominaba Europa, Colbert fundó la Manufacture des Glaces de Miroirs Saint-Gobain, real fábrica de vidrio espejo que funciona desde esa época ininterrumpidamente hasta el día de hoy. Como escribía Voltaire: “Ya en 1666 se produjeron espejos que eran tan hermosos como los que se fabricaron en Venecia, que anteriormente había suministrado a toda Europa, y pronto se hicieron espejos cuyo tamaño y belleza nunca han sido igualados en otros lugares".

Otra fábrica real creada por el ministro, por encargo del rey, es Alençon², donde se manufacturan los famosos encajes que llevan ese nombre. Las encajeras dominan todas y cada una de las fases de realización de este sofisticado producto. El método de aprendizaje era exclusivamente por transmisión oral y práctica presencial, y requerían, por lo tanto, de una estrecha relación entre la maestra encajera y sus pupilas. Otra de las manufacturas emblemáticas creadas en esa época son la Manufacture des Gobelins, de Beauvais (1664) o Aubusson (1664), todas famosas fábricas de tapices que siguen vigentes hasta nuestros días. La tapicería, originaria de Asia, llega a Europa en la época de las cruzadas. Es una técnica artesanal de lo que podríamos llamar tejido de imágenes, generalmente utilizada para crear murales de grandes dimensiones que adornan las paredes de los castillos de piedra y protegen del frío, pero también esas obras cuentan historias, transformándose así en grandes relatos visuales. Otra de sus aplicaciones son las alfombras y tapices para mobiliario.

Estos pequeños ejemplos nos permiten evidenciar el espectacular auge que tienen los "Métiers d'art" en Francia durante el siglo XVII. Como parte de este mismo impulso, un poco más tarde, gracias a la inteligencia de la duquesa Jeanne-Antoinette Poisson, partidaria del proyecto de Encyclopédie de Diderot y una de las más resplandecientes amantes de Luis XV, conocida como Madame de Pompadour, se crean las hoy famosísimas fábricas de porcelana de 
3. Ateliers d'Art de France actualmente es el sindicato profesional representativo de la artesanía. Reúne a más de 6.000 artesanos, artistas y fabricantes de arte, así como 125 asociaciones. El sindicato de La unión de los talleres de arte es el interlocutor de referencia con las autoridades públicas, los profesionales y el público en general. Una fuerza independiente y unida, esta organización se rige por profesionales de la profesión del arte elegidos por sus pares. Sitio Web https://www.ateliersdart.com/ 4. Esta distinción la entrega el Comité Nacional de Artesanía, integrado por el Área de Artesanía del Ministerio de las Culturas, las Artes y el Patrimonio y el Programa Artesanía de la Pontificia Universidad Católica.

5. http://www.mapa.uchile.cl/
Sèvres. Para seguir con esta fuerte tradición, se fundan mediante edicto real de Luis XVI las fábricas de porcelana de la ciudad de Limoges. Se constata que, en ese país, la tradición de más de tres siglos, de valoración, apoyo y respeto a la artesanía en sus distintas manifestaciones ha tenido un efecto concreto en la identidad de esa nación.

Dos siglos más tarde, en 1868, se funda el Ateliers d'Art de France ${ }^{3}$, unión profesional de artesanos de carácter sindical, que abarca todos los ámbitos de esta actividad. La idea central de esta asociación es promover, representar y defender al sector artesanal para de esta forma contribuir al desarrollo económico de los creadores profesionales tanto dentro de Francia como en el espacio internacional. Entre sus múltiples actividades desde su fundación, pero centrándome específicamente en los modos de visibilización de los trabajos de los artesanos, quisiera destacar la creación, en 1949, del Salon des Ateliers d'Art en París que en 1995 se transforma en el Salon Maison \& Objets y, en 2013, la Bienal Internacional de artesanía Révélations, Bienal Internationale Métiers D'Art \& Creation, que en sus cuatro versiones ha sido instalada en el Grand Palais en París. Con gran impacto entre el público y los expositores, este gran evento cultural atrajo a 34.000 visitantes en su primera edición.

La Bienal Internacional Révélations se divide estructural y curatorialmente en tres partes. La primera le corresponde al país invitado de honor que tiene una ubicación privilegiada dentro del espacio de exhibición. El primer país invitado el 2013 fue Noruega, el 2015 le correspondió el turno a Corea del Sur, el 2017 a Chile y el 2019 a Luxemburgo. Cada país propone un concepto curatorial que se discute y trabaja en conjunto con el equipo de Francia. La segunda parte y la más extendida lo constituyen los módulos/estands donde los creadores de toda Francia y algunos de Europa exponen y venden sus trabajos. Cada uno de ellos son seleccionados previa postulación y revisión por el equipo de Ateliers d' Arts.

La tercera parte corresponde a "Le Banquet" que conceptualmente se plantea como un gran homenaje a la diversidad de los continentes y como una posibilidad de construir un diálogo entre las diferentes culturas. En la nave central del Grand Palais se disponen lo que ellos Ilaman islas de exhibición, una serie de archipiélagos que están dispuestos a lo largo de toda la nave separados solo por un par de metros. Cada uno de ellos está dedicado a una región del mundo proponiendo al visitante una mirada hacia creaciones que reflejan la diversidad cultural y creatividad de las artesanías de cada lugar del mundo: "Le Banquet es testigo de la fuerza de la identidad cultural que llevan los creadores de cada país. Desde América Latina hasta Asia, África occidental y Europa continental, cada país transmite su mensaje único".

La primera participación de Chile fue el año 2015 en Révélations, y su montaje se realizó precisamente aquí, en la sección "Le Banquet". En esa ocasión Chile fue el primer país latinoamericano que participó en la Bienal y, a la fecha, extrañamente sigue siendo el único país latinoamericano que ha participado presentando obras de sus creadores.

En esa primera ocasión, la selección de los objetos se realizó entre las piezas ganadoras de Sello de Excelencia Artesanías de Chile, Ministerio de las Culturas, las 


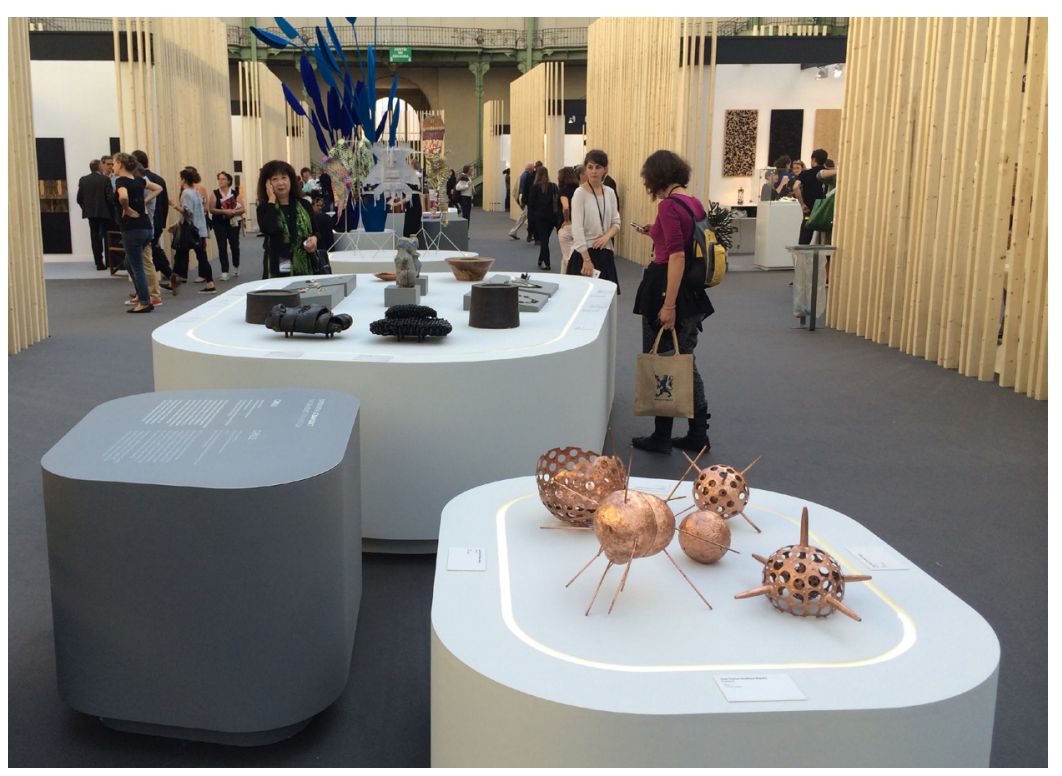

Artes y el Patrimonio MCAP4 que salvaguarda el Museo de Arte Popular Americano Tomás Lago MAPA de la Facultad de Artes de la Universidad de Chile5. En el año 2012, el MAPA forma una alianza colaborativa con el Área de Artesanía del MCAP y su programa Sello de Excelencia Artesanía Chile, organizando la primera exposición de objetos distinguidos con el Sello de Excelencia a la Artesanía. Bajo el nombre de "Objetos chilenos" se exhibieron cincuenta y siete piezas ganadoras de Sello entre los años 2009 y 2011 . Fue una ocasión única para ver reunidos objetos pensados en Chile y realizados por los mejores artesanos nacionales.

A partir de esa exposición, se reconoce al MAPA como un espacio activo de visualización y salvaguarda de las creaciones artesanales, para generar confianza en los creadores, quienes, en su gran mayoría, deciden donar sus piezas para iniciar la Colección Sellos de Artesanía del MAPA, que reconoce y valora la misión de resguardo y divulgación que caracteriza a este museo universitario. Cada objeto se documenta, se le asigna un número de inventario, se registra fotográficamente y se realiza una ficha de conservación y almacenaje, con el fin de resguardar el patrimonio material artesanal para su estudio, conservación y educación. A partir del 2012, se incluye en las bases del concurso que todas las piezas ganadoras de Sello ingresarán a la Colección Sellos de Artesanía del MAPA. Por su parte, el MAPA se compromete a itinerar esta Colección Sellos de Artesanía por diferentes comunas y regiones del país. Muchos de estos objetos han sido imaginados y fabricados en el espacio calmo de la heredad, del juego, del amor esperanzado y la piedad popular que obligan al espectador a desenfocar la mirada sobre el vórtice de las grandes historias. Para reenfocarla en las texturas y en el brillo opaco y mínimo de la superficie manual de estos objetos, que a despecho de ser incausados, intrascendentes, de mera utilidad privada y hogareña, logran traspasar con su gracia todas las épocas de la historia, enhebrando toda la historia de los estilos.

Para responder a esta participación internacional del envío chileno a "Le Banquet" 2015, fui elegida como curadora 6 por Bárbara Velasco, coordinadora nacional de Artesanías del MCAP, en ese entones $\mathrm{CNCA}^{7}$. El pie forzado fue
Figura 1. Fotografía de Revelation (año).

Fuente: Nury González.

6. Nury González, artista visual. Profesora titular de la Facultad de Artes de la Universidad de Chile. Directora del Museo de Arte Popular Americano Tomás Lago MAPA de la Facultad de Artes de la Universidad de Chile.

7. CNCA, Consejo Nacional de las Culturas y las Artes que en 2018 se transforma en Ministerio de la Culturas, las Artes y el Patrimonio MCAP. 
Figura 2. Fotografía de Revelation (año). Fuente: Nury González

8. Juan Carlos Orellana, artesano de Coya, varias veces ganador de Sello de Excelencia y Premio Maestro Artesano Contemporáneo 2014.

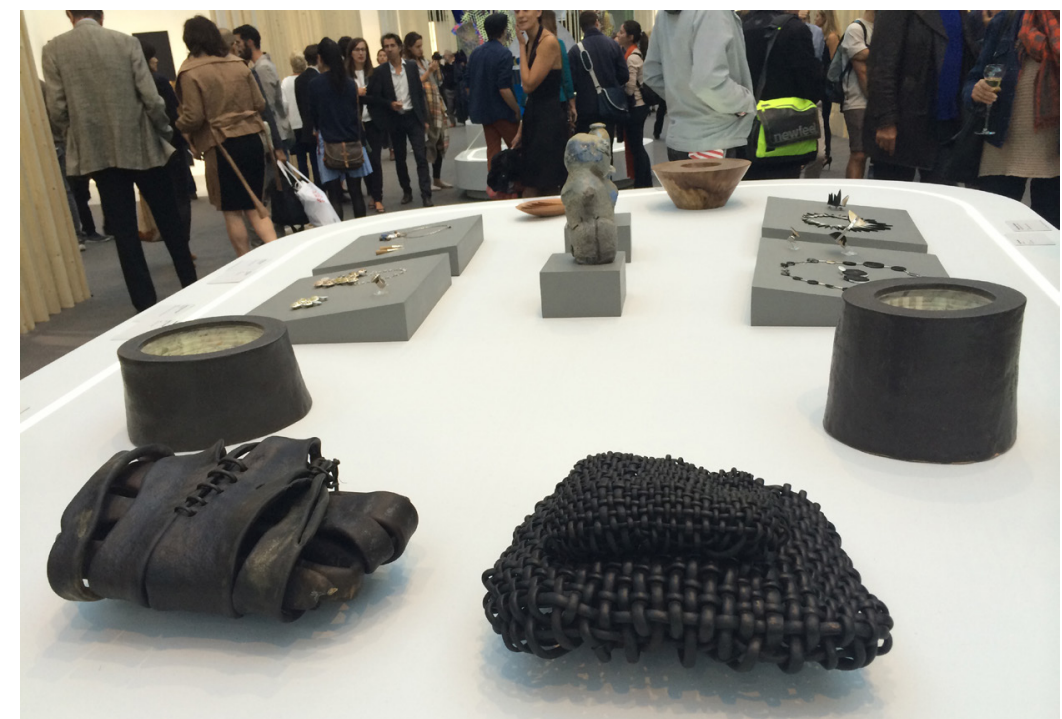

hacer una propuesta a partir de la Colección Sellos de Artesanía del MAPA. La selección de artesanos y artistas fue decidida en base a tres conceptos fundamentales: materiales representativos de nuestro territorio, formas simples y depuradas y finalmente un patrón cromático en escala de grises. La idea fue que la cultura de los pueblos de Chile y sus múltiples materialidades se vieran representadas a través de las obras de ocho creadores contemporáneos. Como trabajo destacado se presentaron las obras realizadas por Juan Carlos Orellana ${ }^{8}$, artesano en cobre, que vive y trabaja en Coya, anclado en la ladera de la montaña junto a uno de los yacimientos de cobre más importantes del país. Su instalación de cinco piezas evocaba el fondo marino, las formas eran inspiradas por las ilustraciones del naturalista y filósofo alemán Ernst Haeckel, uno de los primeros en dibujar los organismos unicelulares de los océanos a fines del siglo XIX. El artista recrea un mundo aparte, un hábitat misterioso, síntesis de la tierra y el océano. Lise Moller presentó lo que ella llama paquetes realizados con un entrelazado denso y flexible de cochayuyo que ella recoge de las costas chilenas. Carlos Reyes propuso objetos de madera de líneas puras y minimalistas construidos con madera de milenarios troncos de árboles caídos en los viejos bosques chilenos. Las joyas de Valeria Martínez entremezclaban lana de oveja teñida con vegetales y atrapadas en redes de plata, mientras que Liliana Ojeda hizo dialogar la plata con la cerámica y sus creaciones recordaban los cordones montañosos que cruzan nuestro territorio. El Taller Walka de los destacados creadores Claudia Betancourt y Ricardo Pulgar -utilizando materiales más tradicionales como el cuerno de buey y la plata- expusieron dos conjuntos de accesorios donde destacaba un espectacular collar que evoca el plumaje del cóndor, ave símbolo de la cordillera de los Andes.

Esta presencia desde el sur total del mundo, muy sobria y minimalista fue la fisura por la cual pudimos entrar a ese imponente espacio de creadores de Francia. Las buenas críticas de los curadores y representantes de Ateliers d'Art hacia la participación de las y los creadores chilenos y pensando en el Centenario de Violeta Parra que sería el 2017, nace la idea de postular a Chile como país de honor. Fue fundamental el apoyo y compromiso de Ernesto 


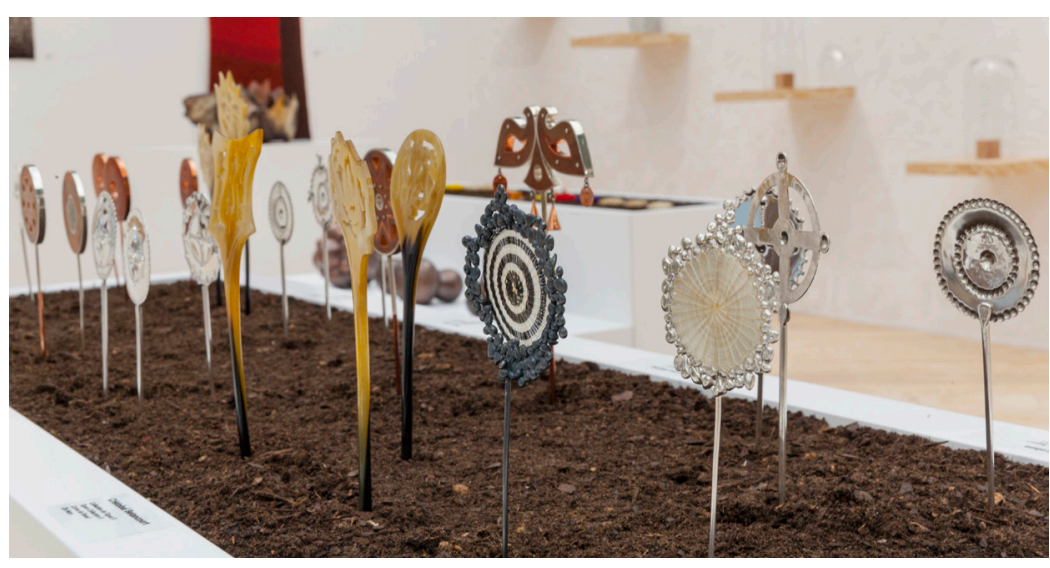

Ottone, ministro de Cultura de la época, también de María Paz Santibáñez, agregada cultural de Chile en Francia y, sobre todo, la firme convicción de Bárbara Velasco, encargada de Artesanía del MCAP que desde siempre ha apoyado y relevado el trabajo creativo de los artesanos chilenos. Finalmente, en marzo de 2016, Chile es elegido oficialmente como país de honor y soy nombrada nuevamente como curadora general del envío chileno. La propuesta de Chile en Francia se enmarca en la celebración del centenario del nacimiento de Violeta Parra, desde ahí se propone una mirada que reflejara la infinita capacidad creativa que tenemos, la multiplicidad de saberes y la riqueza de materias nobles que existen en nuestro territorio, sumadas a una cultura milenaria, pero a la vez muy contemporánea. Finalmente, el concepto general y medular de la exhibición de Chile como país de honor en Révélationsz representó la multifacética territorialidad de nuestro país. El territorio chileno mide más de 4.200 kilómetros de norte a sur con un promedio de apenas 250 kilómetros de ancho, de oriente a poniente. Por eso se dice que es una larga y angosta faja de tierra. Al norte, el desierto más árido del mundo, con largas extensiones de tierras rojas, ocres y violetas. Al sur, verdes e interminables superficies de campos, bosques nativos y también azules glaciares flotando por los canales. Al este, una imponente cordillera de los Andes que desde tiempos remotos atesora en sus entrañas infinitas materias nobles como el cobre, la plata y el oro. Al oeste, el océano Pacífico, más de 4.000 kilómetros de agrestes costas y de playas interminables. Una "loca geografía", a la letra de Benjamín Subercaseaux, que muchas veces Violeta Parra tradujo en alguna de sus múltiples creaciones. Es entonces esta idea -desde lo conceptual, lo simbólico y lo material- la que cruzó cada una de las acciones y propuestas de selección de objetos y puesta en escena que realicé para construir la curatoría general de Chile en Francia.

Se inició así un largo trabajo de preparación para llegar a París con los mejores exponentes que representaran la diversidad que nos caracteriza. Como una forma de orientar a los creadores en sus postulaciones para la exposición, Bárbara Velasco propuso que el tema central del XIV Seminario Internacional de Artesanía` tratara los asuntos de la creación contemporánea y sus nuevas lecturas y líneas de autor.

Se iniciaba así un largo trabajo, lo primero fue realizar una convocatoria nacional para que artesanos, artistas y creadores presentaran propuestas centradas en el imaginario de Violeta Parra. Se recibieron más de 200
Figura 3. Fotografía de Revelation (año).

Fuente: Nury González.

9. Organizado por el entonces Consejo Nacional de la Cultura y las Artes (CNCA) con el apoyo del Museo de Arte Popular Americano Tomás Lago, junio de 2016, Centro Cultural Gabriela Mistral (GAM). 
postulaciones de todo Chile, las que fueron revisadas por mí, como curadora, junto a Romain Juilha, responsable de Proyectos Internacionales de Ateliers d'Art quien viajó especialmente a Chile para esta difícil tarea. En esa ocasión también visitamos más de treinta talleres dentro y fuera de Santiago. Finalmente, se seleccionaron veintisiete propuestas para ser expuestas en el estand de honor de Chile. Las piezas seleccionadas cubrían una gran muestra de materialidades y técnicas que iban desde el textil en lana o algodón, la cerámica, la madera, la plata y el cobre, sin quedar fuera la crin o el cacho de buey. Paralelamente, seleccionamos a los cinco artistas que se presentarían en "Le Banquet", ya que el país de honor también debe exponer en esta sección teniendo, además, el lugar principal de las islas de la nave central. Esta magna empresa cultural solo fue posible gracias al trabajo colaborativo de varias instituciones del Estado chileno, principalmente el Área Artesanía del Ministerio de las Culturas las Artes y el Patrimonio (MCAP), la Unidad de Asuntos Internacionales del MCAP, la Dirección de Asuntos Culturales (DIRAC) del Ministerio de Relaciones Exteriores, ProChile, Imagen Chile, Embajada de Chile en Francia y tantas otras.

El estand que propuse, curatorialmente, a Ateliers d'Art era la casa, esas casas chilenas de madera que son pequeñas o grandes, pero siempre las encontramos a lo largo del territorio, en ciudades y campos. Simbólicamente una casa que contenía toda la poética de la naturaleza y de los creadores chilenos. Para solucionar los aspectos formales de diseño y construcción arquitectónica del estand, el entonces CNCA contrató al diseñador Pablo Núñez. Al interior de la casa, el diseño de montaje para cada pieza lo estructuré desde la geografía de Chile, en su lado más largo, una representación en escala de grises de la cordillera de los Andes y al mismo tiempo de los glaciares. Sobresalían de ella pequeñas repisas de madera, como árboles colgantes que sostienen joyas que han sido creadas con sus minerales, especialmente oro negro y piedras preciosas diseñadas por el Taller Walka. Se intercalaban por las impactantes joyas mapuches del destacado rütrafe Marcos Paillamilla, afamado platero mapuche. Al frente, como sucede en nuestra geografía radicalmente cambiante, un muro celeste como el espumoso mar del cual colgaban las obras tejidas con cochayuyo de Lise Moller y también platos de porcelana con texturas de fondos marinos de Tere Marín. Sobre los muros perpendiculares, se desplegaban los textiles de las artistas Paola Moreno, Carolina Irarrázaval, Paulina Brugnoli y Constanza Urrutia. Muchos de ellos desde sus texturas y cromías nos recordaban a Violeta Parra. Al centro, plintos blancos dispuestos como pequeños bosques que sostenían los delicados objetos realizados con materias de nuestra tierra: un bosque de tupus de plata, filigrana de cacho de buey, picoyo, cobre o plata y crin de Cristian Molina, Juan Lobos o Cristóbal Betancourt, todos enterrados en tierra; una cordillera de cachos de buey con oro y sorprendentes collares, verdaderas obras de arte de cacho de buey y lana también del Taller Walka; un jardín de camelias de crin de caballo de múltiples colores creados por Eliana Carter de Rari, todos dispuestos sobre tierra húmeda; una escultura de crin de caballo y oro realizada por el gran diseñador Mauricio Clavero en colaboración con artesanas de Rari. También se encuentra una extensa colección de finas peinetas de cacho de buey del destacado artesano Juan Betancourt; fuentes de madera realizadas por Egon Muñoz con restos de árboles milenarios recogidos en los faldeos del volcán Villarrica; fuentes minimalistas de madera reciclada de Claudio Reyes; formas orgánicas 


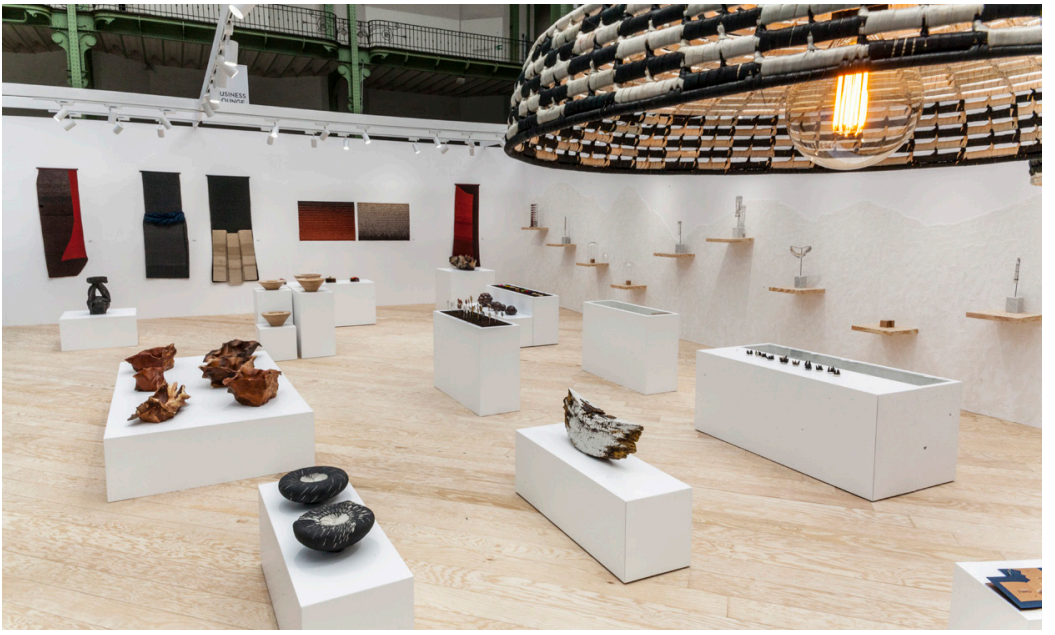

realizadas en cobre por Jorge Orellana. Objetos de gres que recuerdan cordilleras de Pascale Lehman o formas orgánicas de Ruth Krauskopf; lámparas de fibras vegetales de las artesanas de la agrupación Ñocha Malen; estilizadas sillas de mimbre del recordado Rodolfo Castro, de Chimbarongo. Todos ellos, desde sus propios y particulares imaginarios, son creadores chilenos que producen pequeñas y grandes obras que se despliegan aquí como fragmentos de nuestra cultura homenajeando a Violeta Parra. Casi la totalidad de los artesanos viajaron a París invitados por el Área Artesanía del MCAP, ya que la idea principal de Bárbara Velasco era que cada uno de ellos tuviera la experiencia de ver sus trabajos expuestos junto a los mejores artesanos franceses. También era importante que pudieran mirar, admirar y aprender del trabajo de los otros. Muchos de ellos dialogaron e intercambiaron ideas con los expositores de todas las regiones de Francia. Aparecieron ahí muchas coincidencias en los modos de trabajar y también mucho traspaso de saberes. El encuentro con la cultura francesa, especialmente con las colecciones de los museos y con la arquitectura de la ciudad, también fue una experiencia inesperada y muy valorada por todos ellos y ellas.

En “Le Banquet”, donde mi curatoría fue compartida con Romaín Juilha, se presentaron las obras de Cristián Salineros, Bernardo Oyarzún, Elisa Aguirre, Paula de Solminihac y Marcela Undurraga. En todas estas obras la forma y la materia eran las grandes protagonistas que causaron gran impacto en el público.

En las reuniones de evaluación que tuve con Ateliers d'Art, días después de terminada la Bienal, una de las cosas más significativas que comentaron los organizadores fue que para ellos Chile había sido una real y verdadera revelación, de cierta forma la propuesta chilena cumplía exactamente con el concepto que ellos plantean para esta Bienal y es que algo sea revelado a la mirada de los otros. Como dice el Diccionario de la Real Academia Española, una de las acepciones de la palabra revelación es: "Manifestación de una verdad secreta u oculta". Pareciera que algo de eso había en las obras expuestas, fue muy curioso que los mismos chilenos que circulaban por el Grand Palais se sorprendían de la calidad y creatividad de los artesanos chilenos. Muchos comentaban que nunca habrían imaginado que en Chile se hacían esos objetos tan contemporáneos y bellos. Para quienes expusieron creo que también
Figura 4. Fotografía de Revelation (año). Fuente: Nury González 


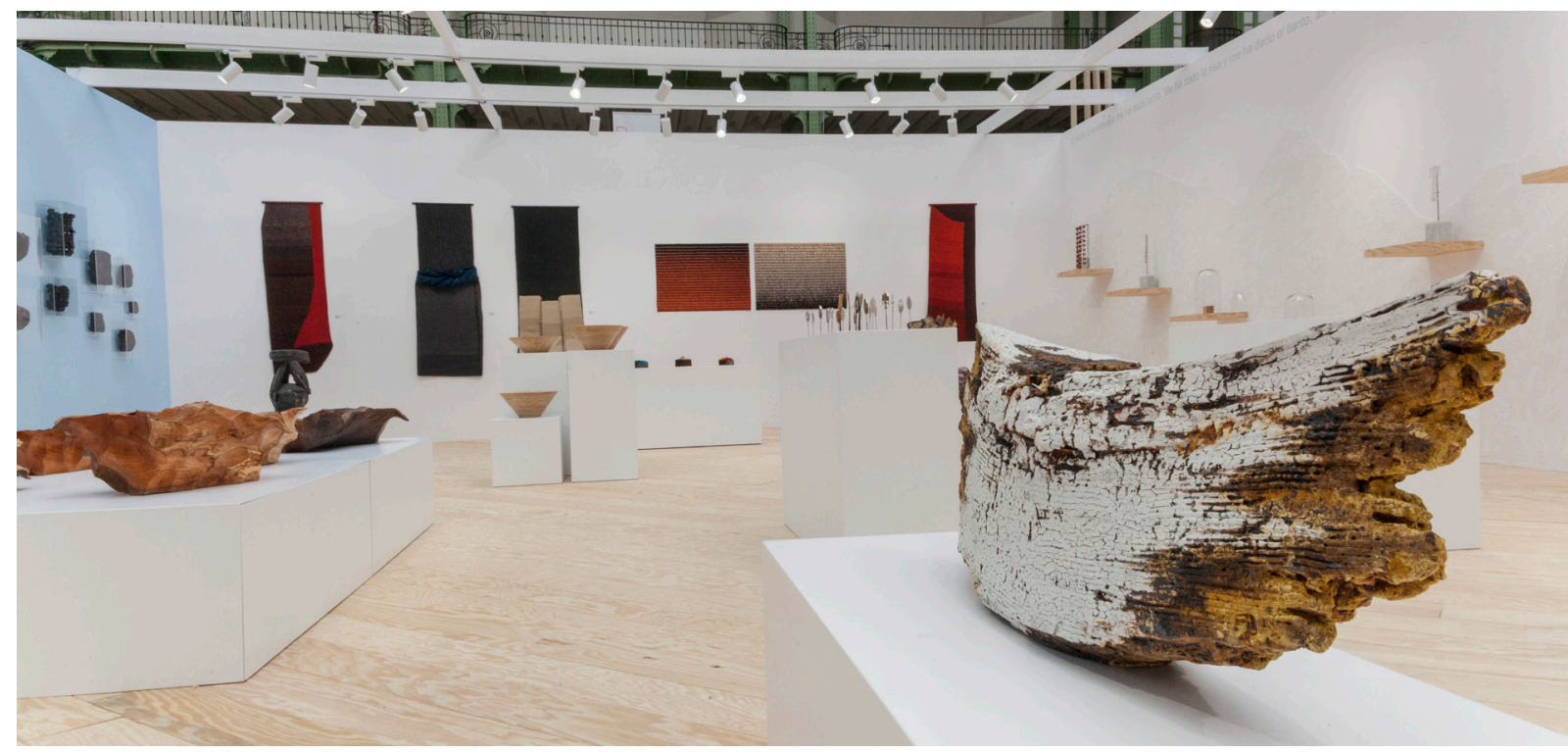

Figura 5. Fotografía de Revelation (año). Fuente: Nury González fue una experiencia reveladora, aprendieron a valorar mucho más sus propios trabajos, pero sobre todo a sentirse orgullosos de quienes son y del trabajo que realizan. Paralelamente, pudieron observar que existen modos exitosos de asociatividad que dependen de los mismos artesanos, sin embargo, como lo dije al inicio, Francia tiene más de 300 años de valoración de sus artesanías. Es por esta razón que el mismo año 2017, el tema del XV Seminario Internacional de Artesanía fue "Desafíos y reflexiones para la Artesanía en un contexto global: el futuro de lo hecho a mano", ocasión en que se expusieron diferentes formas colaborativas con las cuales los artesanos podrían agruparse.

En 2019, Chile por derecho propio estuvo presente en Revelations4, ya que así está estipulado en la organización de esta Bienal. El país que ha sido país de honor se presenta en "Le Banquet" de la versión siguiente sin tener que postular. En esta ocasión, el curador fue Mauricio Clavero y se expusieron las obras de seis artistas. Paralelamente, Chile estuvo presente en un pequeño estand con la participación de más de diez creadores entre artistas y artesanos. Por lo tanto, ha existido una continuidad con la presencia de Chile en ese importante espacio de exhibición para la artesanía y el arte.

Para terminar, quisiera destacar muy especialmente a Egon Muñoz quien vive en Pucón y fue uno de los artesanos que el 2017 viajó a París con sus obras. Desde ese momento su trabajo ha sido reconocido y valorado tanto en Chile como en Francia, pero principalmente por él y su entorno. Egon, que vive a los pies del volcán, tiene varios locales de ventas de artesanías, sin embargo, actualmente está construyendo un increíble espacio de exhibición para sus obras. Pero lo interesante es que también será un taller abierto a los visitantes, porque se dio cuenta que ese saber que él tiene es algo valorado y a los otros le interesa observar. Hay aquí una propuesta y una mirada sobre su propio trabajo creativo que será enriquecido, ya que su proyecto a futuro es invitar a otros artesanos a exponer sus obras. Quizás es el inicio de una nueva forma de relacionarse con el medio y estoy segura de que la experiencia de Revélation fue fundamental para el desarrollo de su trabajo. 